\title{
Winding Pathways to Engagement: Creating a Front Door
}

\author{
Lori E. Kniffin \\ University of North Carolina at Greensboro
}

\author{
Timothy J. Shaffer and Mary H. Tolar \\ Kansas State University
}

Service-learning and community engagement (SLCE) practitioner-scholars - meaning all who do the work of SLCE with a commitment to integrating practice and study - find avenues to this work in a variety of ways. Many of the thought leaders in this movement started as traditional scholars in their disciplines and, only in their later careers, focused on creating and enhancing SLCE on their own campuses and across the academy. Others first learned about SLCE as an epistemological framework and a pedagogy in graduate programs such as Curriculum and Instruction or Higher Education Leadership. Others came across it during their academic careers somewhat randomly in conversations with colleagues, at conferences, or in the literature. And still others began their journey to SLCE by working in the public sector (as did co-author Mary Tolar) with community organizations, as community organizers, or as social justice advocates. Members of a younger generation of practitioner-scholars have now experienced SLCE in undergraduate or graduate education and seek ways to integrate it into their academic or professional lives from the very beginning.

The edited volume Publicly Engaged Scholars: Next Generation Engagement and the Future of Higher Education (Post, Ward, Longo, \& Saltmarsh, 2016) highlights the emergence of this "next generation" of SLCE practitioner-scholars. It offers an intriguing contrast to the question raised twenty years ago by Edward Zlotkowski (1995) of whether SLCE had a future and, if so, what it would need to flourish. Looking back to that moment twenty years ago in his 2015 framing essay for the ServiceLearning and Community Engagement Future Directions Project (SLCE-FDP), Zlotkowski notes that it was "a good time to dream of a new era" (p. 82 ); and he ponders what the forces currently shaping the academy and democracy in the U.S. mean for the SLCE movement. Publicly Engaged Scholars strongly suggests there is currently considerable momentum and excitement around a reimagined future for SLCE. The narratives of 22 engaged scholars from both the academy and the broader community (including co-author Timothy Shaffer) make clear the progress of SLCE in recent decades.
And yet, they also reveal dissatisfaction with where we are today and call for continued evolution of the movement.

The stories of these next generation practitionerscholars, including their winding paths into SLCE, suggest to us the importance of supporting the ongoing development of the SLCE movement through more explicit, direct, formalized, and institutionalized points of entry into the work. Many of them went through the academy as graduate students and now work either on campuses or in communities across wide ranging professions. Indeed, graduate-level education is an increasingly common component of such journeys. It is not, however, an unambiguous point of entry to SLCErelated careers. Therefore, in this essay we call for increased attention to the potential of graduate education to serve as a doorway into SLCE. And we suggest the importance of designing graduate-level study with an eye to shaping how incoming SLCE practitioner-scholars understand and undertake the work (e.g., with an asset-based rather than a deficitbased orientation; as an integrated part of their lives rather than an add-on to other responsibilities).

Co-author Lori Kniffin's own journey provides an example of the presently common winding path into SLCE taken by members of the next generation of practitioner-scholars:

I experienced SLCE first as an undergraduate student in an introductory course in a leadership studies program. When I later joined the same department as a staff member and then as an instructor while completing my master's degree, I learned that the kind of SLCE I had experienced had a lot of room for improvement. I started participating in conversations to improve that course using best practices in the SLCE literature. I also dove into a community engagement experience through a leadership practicum I taught; its evolution over eight semesters - from simply meeting with community organizations that worked in the area of food security to listening to the experiences of individuals experiencing food insecurity and ultimately helping build a network to improve food security on campus - mirrored my own ever-deepening understanding of SLCE. 
This rich mix of first-hand experiences with the challenges and possibilities of SLCE increased my desire to pursue a Ph.D. in a program that would allow me to immerse myself in SLCE and prepare me to be a community-engaged practitioner-scholar. Disappointed with the lack of opportunities for community engagement in my master's program, I began looking for a doctoral program that focused on SLCE both as a mode of teaching and learning and as the focus of scholarship. I had numerous conversations with SLCE colleagues, searched online, contacted many colleges and universities... and yet all of this yielded no clear answer as to my best options for a doctoral program.

So I did what I have since learned many graduate students do: I pulled together bits and pieces of an engaged graduate education into a whole that met most of my goals. I entered a fairly traditional academic unit that is oriented toward social justice and has flexible requirements, and I also became part of an innovative community engagement institute on campus through a graduate assistantship. And probably most importantly, I surrounded myself with other practitioner-scholars with whom I collaborate on a variety of SLCE-related projects. This combination of opportunities will, I hope, serve me well as I complete a Ph.D. and continue my career. But I still wonder why this patchwork approach seems to be the best avenue I could come up with and why I could not readily find a graduate program that could more explicitly and coherently support my interest in pursuing SLCE as an integral part of my scholarly development.

This story, although unique in its specifics, has similarities to other narratives of SLCE practitioner-scholars, including a good number of those assembled in Publicly Engaged Scholars and previously in Collaborative Futures: Critical Reflections of Publicly Active Graduate Education (Gilvin, Roberts, \& Martin, 2012). Through custom-made pathways such as this, graduate students are forced to articulate and define their place in the academy, which can enhance voice, confidence, relationships, and identity exploration. Too often, however, students have to settle for a fairly traditional department as their primary academic home and seek out more innovative opportunities for learning and research elsewhere. When students enter a discipline-centered program, their studies must focus on deep understanding of and scholarly contributions within that discipline, often to the exclusion of study at the intersection of disciplines. Graduate students who want to self-define as SLCE practitioner-scholars thus experience identity fracturing, finding themselves needing to wear distinct "hats" as they move between disciplinary work in their departments and SLCE-related work in other arenas of their lives. Worse, students without a high level of persistence, the resources to devote significant time and attention to the search for a program, and/or strong connections in the field may never find these pathways - with the consequence that the SLCE movement may lose their participation and leadership. Further, the movement may disproportionately lose the voices of students who lack the privilege of access to the human, cultural, and economic capital needed to pursue such winding pathways toward SLCE.

We therefore believe that unclear, winding paths serve as a significant deterrent to growing the SLCE movement. The movement is more likely to flourish in the future if we create a "front door" to SLCE in the form of graduate education explicitly designed to integrate SLCE practice, study, work, and scholarship. Enhancing opportunities for doctoral education in particular as a point of entry could open up many new possibilities for more people - and for a greater diversity of people - and thereby grow the SLCE movement. Advanced graduate education is where many who choose an academic career or a research-oriented profession in the nonprofit sector develop their professional identities and internalize the habits, dispositions, and skills of scholarly work. Developing the perspectives and capacities associated with democratic engagement as part of this process would deeply influence the identities and practices of community-engaged practitionerscholars.

We recognize there may always be a tension in doctoral education regarding employment opportunities for graduates with non-traditional degrees. However, we see signs that bode well for the career prospects opened up by doctoral programs that integrate SLCE: (a) the growing recognition of the complexities of challenges facing us, local to global, in the 21st century (see, for example, the United Nations Sustainable Development Goals); (b) the increasing demand in the public sector for advanced, interdisciplinary, community-engaged research to generate knowledge and inform policy; and (c) the increasing number of next generation practitioner-scholars who are undertaking such graduate work and successfully creating meaningful career paths for themselves on campuses and in communities (see Post, Ward, Longo, \& Saltmarsh, 2016).

We share here an example of a "front door" we have been building to illustrate an approach to doctoral education that could support the holistic development of SLCE practitioner-scholars. At Kansas State University, we have recently created and are preparing to launch a new program that 
integrates community-engaged scholarship. This Ph.D. in Leadership Communication is a collaboration among three departments in three different colleges: Communication Studies (College of Arts and Sciences), the Staley School of Leadership Studies (College of Education), and Communications and Agricultural Education (College of Agriculture). The fourth unit involved is the Institute for Civic Discourse and Democracy, whose mission is to build community capacity for informed, engaged, civil deliberation.

The program is labeled in accordance with campus models as "interdisciplinary," but the faculty are still sorting through the appropriateness of "multi-," "inter-," and "trans-" disciplinary framings. The program will bring together students and faculty from multiple disciplines (some of which are themselves interdisciplinary), will nurture synthesis and integration among these disciplines, and will advance public problem-solving by transcending the boundaries of disciplinary or academic perspectives and incorporating community-based knowledge. Given the program's role as a front door into SLCE for graduate students coming from various backgrounds and its defining focus on cultivating civic leadership and collaborative change agency, we need to think carefully with students about the significance of "interdisciplinary" and "transdisciplinary" framings for communityengaged practitioner-scholarship and ensure that the program launches and grows accordingly.

Faculty and staff from the four units convened over the course of a year to co-create learning outcomes, courses and curriculum, and assessment strategies. The core curriculum developed by these units will be co-taught, with teaching responsibilities rotating amongst departments. Students will have the opportunity to choose major professors and dissertation committee members from the three academic units as well as from affiliate faculty across the university. Key to the program's function as a doorway into SLCE, then, is that students will have the freedom and flexibility to tap into the expertise of a range of faculty who support diverse approaches to SLCE and establish direct connections with community-engaged faculty.

Students will not only learn how to do community-engaged scholarship but will learn by doing community-engaged scholarship. Two of the core courses include theoretical foundations and application of community-engaged methods. The program requires students to develop community relationships, work with community organizations on public problems, and co-create scholarship with community members. We imagine dissertations that push the boundaries of traditional products to include artifacts accessible and useful to the general public and that demonstrate measurable progress being made with community partners on public issues. This model recognizes the disciplinary expertise students bring with them but focuses on how that is connected with other knowledge and leveraged for change through community-engaged scholarship. With an active, experiential learning orientation, throughout their engaged doctoral study and practice students will have the opportunity to develop and exercise the capacity to lead change in and with communities. They will, relatedly, work with one another, community members, faculty, and staff to develop innovative ways to assess progress achieved through collaborative change strategies - this being a major challenge both in the curriculum and in the work itself.

Although community engagement is at the center of this program, it is not a Ph.D. in engagement, and we do not advocate for SLCE as a siloed discipline but rather a cross-disciplinary approach to teaching, learning, and research (see Clayton, Edwards, \& Brackmann, 2013 for discussion of next generation engagement perspectives on calls to frame SLCE as a discipline). Our aim is for graduates to be prepared for deeply collaborative work with communities as civic leaders and change agents, whether in higher education, government, nonprofits, or socially responsible businesses. They will need to understand SLCE from the very beginning as constrained neither by disciplinary lenses nor by academic orientations to knowledge and practice. Students will study and integrate multiple disciplines and combine this learning with knowledge and methods of community-engaged scholarship.

This doctoral program is just one example of what we think a front door could look like for graduate students. The important thing is that we find ways to cultivate interest in and access to community-engaged work instead of letting passionate people get lost or discouraged along the way. Beyond the need for such points of entry, per se, we have a lot of work to do to transform institutions of higher education so that they better support the work of SLCE (on the other side of the front door, as it were) and better organize to address complex issues in our world (for many, the reason for looking for a doorway to begin with). We believe these goals as well can be advanced through the design of graduate-level front doors.

As we create spaces for graduate students from many disciplines to collaborate with engagement as the central thread, we also create learning communities that connect faculty from many disciplines who share commitments to SLCE and who can, 
by coming together to deepen their engaged work, have greater influence over institutional change processes and priorities (see O'Donnchadha, 2015). For co-author Timothy Shaffer, as one example, such a network of faculty, students, and community members interested in community-engaged scholarship provides a place for collaboration and affirmation. Further, for many of his colleagues, a space such as the new doctoral program at Kansas State serves as their own front door into SLCE, providing a supportive environment for them, regardless of their home disciplines, to learn about and begin incorporating community-engaged teaching and research into their work. For both veteran and new SLCE practitioner-scholars, a graduate program such as this offers a community of colleagues who view such work as not only legitimate but also important. And that community, in turn, can have a strong voice in campus conversations about policy changes and other aspects of systems change that are key to any higher education institution's ongoing integration of community-campus engagement as central to its identity.

Community-engaged academic programs such as this one can at the same time help to organize and focus efforts that bring campuses and communities together to address public issues that transcend single disciplines or sectors. The United Nations' Sustainable Development Goals outline several such complex challenges the SLCE community can help address. Food security is one of these challenges, and advancing food security globally requires practitioner-scholars in the humanities, social sciences, and natural sciences to employ collaborative leadership and work in partnership with communities. The National Science Foundation's recognition that robust research can and must engage the public similarly provides an impetus to design graduate programs that work across disciplines and cultivate engaged learning communities oriented toward making progress on the complex global issues we face in this century.

There are many possibilities ahead for SLCE, especially as new generations of practitioner-scholars come into the movement. Individuals already working in SLCE have a responsibility to make the invitation into this work compelling and clear - to institutionalize, formalize, and broaden pathways toward engagement. Creating a front door for graduate students is one way to accomplish this, and we invite colleagues to make more visible their own examples of graduate programs that are being designed as alternatives to winding pathways. We also commit ourselves - and call on others - to create additional clear paths for SLCE practitionerscholars to enter our community. As we see it, the
SLCE-FDP itself serves as a front door: a space that will push the SLCE movement forward by convening and cultivating new voices, including both the next generation of practitioner-scholars and the many actual and potential participants who have valuable, if not yet heard, perspectives. We believe these front doors will broaden and strengthen the next generation of engaged scholars and empower them to advance the SLCE movement over the next twenty years and beyond.

\section{References}

Clayton, P. H., Edwards, K, E., \& Brackmann, S. M. (2013). Disciplining service-learning and the next generation engaged campus. Michigan Journal of Community Service-Learning, 19(2), 80-88. http://hdl.han dle.net/2027/spo.3239521.0019.207

Gilvin, A., Roberts, G. M., \& Martin, C. (Eds.). (2012). Collaborative futures: Critical reflections on publicly active graduate education. Syracuse, NY: The Graduate School Press.

O’ Donnchadha, B. (2015). Critically-reflective civicallyengaged academics shaping the future of an academy striving for social justice. Michigan Journal of Community Service Learning, 22(1), 109-112.

Post, M. A., Ward, E., Longo, N. V., \& Saltmarsh, J. (Eds.). (2016). Publicly engaged scholars: Next generation engagement and the future of higher education. Sterling, VA: Stylus.

United Nations Development Programme. (2015). 2030 agenda for sustainable development. New York. http:// www.undp.org/content/undp/en/home/sustainabledevelopment-goals.html.

Zlotkowski, E. (1995). Does service-learning have a future? Michigan Journal of Community Service Learning, 2(1), 123-133. Retrieved from http://hdl.handle. net/2027/spo.3239521.0002.112

Zlotkowski, E. (2015). Twenty years and counting: A framing essay. Michigan Journal of Community Service Learning, 22(1), 82-85.

\section{Authors}

LORI E. KNIFFIN (lekniffi@uncg.edu) is a doctoral student in Cultural Foundations of Education and a graduate assistant at the Institute for Community and Economic Engagement at the University of North Carolina at Greensboro. Her scholarly interests include food justice, community dialogue, and democratic classrooms. She is the 2016-2017 SLCE Future Directions Project Fellow and Chair of the International Association for Research on Service-Learning and Community Engagement (IARSLCE) Graduate Student Network.

TIMOTHY J. SHAFFER (tjshaffer@k-state. edu) is an assistant professor in the Department of Communication Studies and assistant director of 
the Institute for Civic Discourse and Democracy at Kansas State University. His research interests focus on the advancement of democratic engagement through deliberative democracy and citizen engagement in higher education and community settings. He is co-editor of Deliberative Pedagogy: Teaching and Learning for Democratic Engagement (2017) to be published by Michigan State University Press.

MARY H. TOLAR (mtolar@k-state.edu) is director of the Staley School of Leadership Studies at Kansas State University. She works with faculty and staff to provide learning experiences for more than 1000 students in an interdisciplinary leadership studies minor as well as for the wider campus community through the School's array of applied learning programs. Her research interests focus on the art and practice of civic leadership development, women's pathways to public service leadership, and undergraduate leadership development through applied learning. 